\title{
Determinants of overweight and obesity among Bangladeshi diabetic women of reproductive age
}

\author{
Jesmin Akter ${ }^{1 *}$, Mohammad Shahjahan², Sharmin Hossain ${ }^{3}$, Hasina Akhter Chowdhury ${ }^{4}$, Kazi Rumana Ahmed ${ }^{3}$, \\ Kaniz Fatema ${ }^{5}$, Begum Rowshan Ara $^{1}$ and Liaquat Ali $^{6}$
}

\begin{abstract}
Background: Several reproductive disorders with overweight and obesity are now known to be associated with insulin resistance. The study was aimed to assess the proportion and determinants of overweight and obesity among diabetic women of reproductive age.

Methods: This cross-sectional analytic study was conducted among 888 diabetic women of reproductive age attending the out-patient department (OPD) of the central hospital of the Diabetic Association. Body Mass Index (BMI) was used to assess the general obesity. Waist Circumference (WC), Waist-Hip Ratio (WHR) and Waist-Height Ratio (WHtR) were used to assess central obesity.

Results: The overall prevalence of overweight was $22 \%(95 \% \mathrm{Cl} 19-24)$ and that of obesity was $48 \%(95 \% \mathrm{Cl} 45-51)$. Prevalence of central obesity by waist circumference was $77 \%$, by waist-hip ratio was $99.9 \%$ and by waist-height ratio was $89 \%$. Overweight and obesity were higher in the age group of $45-49$ years (49\%) and 35-44 years (24\%) respectively. On Pearson's correlation analysis, BMI and WC were significantly correlated with age $(r=0.135, p=0.001$; $r=0.162, p=0.001)$ and income $(r=0.151, p=0.001 ; r=0.087, p=0.009)$ respectively. WHR was also correlated with income $(r=0.094, p=0.005)$. Moreover, WHtR was significantly correlated with age $(r=0.139, p=0.001)$, income $(r=0.069, p=0.04)$ and duration of diabetes $(r=0.073, p=0.03)$.

On binary logistic regression analysis, BMI was significantly associated with age, income and management of diabetes by Oral Hypoglycemic Agent $(\mathrm{OHA})(\mathrm{p}<0.05)$. WC was significantly associated with age, income and management of diabetes by OHA and insulin $(p<0.05)$. Where, WHR was significantly associated only with duration of diabetes $(p<$ $0.05)$. WHtR was significantly associated with age $(p<0.05)$, management of diabetes by $\mathrm{OHA}(p<0.05)$ and insulin $(p<0.05)$ in this analysis.
\end{abstract}

Conclusions: A high prevalence of both overweight and obesity exists in diabetic women of reproductive age in Bangladesh and it seems to be associated with increasing age, income, duration of diabetes, and use of oral hypoglycemic agents.

Keywords: Overweight and obesity, Diabetes, Reproductive age, Bangladesh

\section{Background}

Obesity is increasing at an alarming rate throughout the world and has become a global problem [1]. The World Health Organization (WHO) has declared overweight as one of the top of 10 health risks in the world and one of the top five in developed nations [2]. According to recent estimates, there are more than one billion overweight people worldwide, and some 250 million of these are

\footnotetext{
* Correspondence: jesminmasud7@gmail.com

'Department of Reproductive and Child Health, Bangladesh University of Health Sciences (BUHS), Darus Salam, Mirpur, Dhaka 1216, Bangladesh Full list of author information is available at the end of the article
}

estimated to be clinically obese [3], equivalent to $7 \%$ of the world adult population. Once considered a problem related to affluence, obesity is now fast growing in many developing countries and in poor neighborhoods of the developed countries $[4,5]$. Nowadays, there is an increasing trend of overweight and obesity is found to be common in Bangladesh [6]. Incident of rapid demographic transition, sustainable economic development, rapid urbanization, and changing lifestyle and dietary patterns are some of the important causal factors for the emergence of overweight and obesity in developed and developing countries [7]. 
The etiology of obesity is multi factorial. Poor diet and physical inactivity cause overweight and obesity. This imbalance between food intake and energy expenditure is determined, in large part, by the socioeconomic context. Although obesity is affected by interaction between multiple genes and the environment, the genetic pool is not changing rapidly; it is the environmental and social context that has changed and caused the epidemic [8].

Furthermore, this chronic condition has been linked to the development of diabetes and cardiovascular disease, endometrial, colon, postmenopausal breast, and other cancers; and certain musculoskeletal disorders, such as knee osteoarthritis later in life [9]. It is also a critical public health problem for women of reproductive age. Obesity has been associated with both short- and longterm health effects for women as well as for their offspring's. Existing research supports a link between obesity and conditions that impair a woman's ability to conceive and increase her risk for an adverse pregnancy outcome $[10,11]$.

There is a large literature demonstrating that women who are overweight are at greater risk of developing pregnancy complications and problems associated with labor and delivery. Finally, obese women are more at risk of postpartum complications. Taken all complications, maternal mortality and morbidity is significantly elevated for obese women [12-14]. Maternal obesity is also related with health hazards for the fetus and the newborn. Obese women are more likely to give birth to a fetus with congenital anomalies overweight and to have infants who are exposed to a significantly higher perinatal morbidity rate [15]. The effects of maternal obesity do not stop at birth - research has shown that babies born to obese mothers are at greater risk of later developing diabetes, cardiovascular disease and obesity themselves [16].

In most regions of the world, overweight now exceeds underweight among women of reproductive age [4]. Obesity is the tip of the iceberg of a cluster of cardiovascular disease (CVD) risk factors, including hypertension and dyslipidemia. The natural consequence will be an epidemic of cardiovascular complications among diabetic patients, such as coronary heart disease and stroke as well as microvascular complications. Obesity also increases the risk of several reproductive disorders, negatively affecting normal natural function and fertility [17].

In Bangladesh recently the overweight and obesity among the women of reproductive age is increasing [18]. From this point of view, an intensive research on the dynamics of obesity is needed to understand this upcoming health issue and formulate effective programs to enhance the quality of life of the people. However, due to paucity of data, understanding of the causes and consequences of this rapidly growing public health threat remains poor. Therefore, this study is an attempt to understand the dynamics of obesity among women in Bangladesh perspective. The objective of the present study was to assess the proportion and determinants of overweight and obesity among diabetic women of reproductive age attending a tertiary hospital in Bangladesh.

\section{Methods}

This cross-sectional analytic study was conducted among 888 diabetic women of reproductive age attending the out-patient department (OPD) of Bangladesh Institute of Research \& Rehabilitation on Diabetes, Endocrine and Metabolic Disorders (BIRDEM), Dhaka. BIRDEM is a central tertiary hospital of the Diabetic Association of Bangladesh. Diabetic patients from all over the country including referred patients from allied associations are destined here. Being a charity the hospital attracts patients with different demographic and socioeconomic background from all over the country. Thus, data generated from this hospital may be considered as a fair reflection of general diabetic population of the country.

The duration of the study extended for 9 months during May 2011 to January 2012. Data were collected using a semi-structured questionnaire by face to face interview. Purposive sampling technique was used during data collection. No such data were available for Bangladeshi reproductive diabetic population so far reviewed. The prevalence of diabetic women were found from the summarized data of Knowledge Attitude and Practice (KAP) study for World Diabetes Foundation (WDF) 05131 and considered here for estimating the study sample [19]. Patients were asked to control their diabetes as lifestyle management (diet and exercise), insulin and $\mathrm{OHA}$ or Insulin/OHA combination. 24 hours dietary recall method was used to calculate energy intake of the study subjects. Duration of diabetes was $1-13$ years. The socio-economic classification in this study was made according to 2006 Gross National Income (GNI) per capita and using the calculation of World Bank (WB) [20] (The groups were: low-income $\$ 75.41$ or less (BDT $\leq 5360)$, lower middle-income $\$ 75.5$ - \$299.58 (BDT 5361-21270), upper middle-income $\$ 299.68$ - \$926.25 (BDT 2127165761 ) and high-income $\$ 926.33$ or more (BDT $\geq 65762)$ ).

The weighing machine (Model number: RGZ-160, China) was used for measuring the body weight. Before using the machine every time the balance was rectified. Body weight was measured in bare foot having light clothes (nearest $0.1 \mathrm{~kg}$ ). Participants were informed to come for measurement in empty stomach and empty bladder. Height was measured in bare foot in standing position with a standard scale to nearest $0.1 \mathrm{~cm}$. At the time of measuring height, the participants were instructed to stand straight with eye looking forward, head positioned horizontally, feet together and knee straight. The participants were asked to stand and hold their own gown. 
Then examiner found an imaginary point crossing the horizontal line of iliac crest and the midaxillary line of the body. Then the participants were requested to lower slightly the pants and underclothing to palpate directly on the hip area for the iliac crest. Then waist circumference was measured by a measuring tape, using it parallel on those points. The measurements were made at minimal respiration to the nearest $0.1 \mathrm{~cm}$. Hip circumference was measured at the greatest protrusion of the buttocks just below the iliac crest. The measurement was taken in centimeters.

BMI [WHO Guideline for South East Asian (SEA) population] was used to assess the general obesity. Waist Circumference (WC, IDF criteria for SEA population), Waist-Hip Ratio (WHR, IDF criteria for SEA population) and Waist-Height Ratio (WHtR, IDF criteria for SEA

Table 1 Demographic and socio-economic characteristics of the study subjects $(n=888$ )

\begin{tabular}{|c|c|c|}
\hline Variables & Number & Percentage \\
\hline Age (Mean $\pm S D)$ & \multicolumn{2}{|c|}{$39 \pm 7$} \\
\hline $15-24$ yrs & 35 & 3.9 \\
\hline $25-34$ yrs & 181 & 20.4 \\
\hline $35-44$ yrs & 388 & 43.7 \\
\hline $45-49$ yrs & 284 & 32.0 \\
\hline \multicolumn{3}{|l|}{ Occupation } \\
\hline Service & 27 & 3.0 \\
\hline Housewife & 843 & 94.9 \\
\hline Others & 18 & 2.1 \\
\hline \multicolumn{3}{|l|}{ Education } \\
\hline Illiterate & 256 & 29 \\
\hline Primary & 378 & 43 \\
\hline Secondary up to HSC & 204 & 23 \\
\hline Graduate and above & 50 & 5 \\
\hline \multicolumn{3}{|l|}{ Socio-Economic status } \\
\hline Low income $(<5360)$ & 152 & 17 \\
\hline Lower middle income (5361-21270) & 511 & 58 \\
\hline Upper middle income (21271-65761) & 195 & 22 \\
\hline High income (>65762) & 30 & 3 \\
\hline Duration of diabetes (in years) (Mean $\pm S D$ ) & \multicolumn{2}{|c|}{$4.9 \pm 4.3$} \\
\hline$<5$ years & 616 & 67 \\
\hline $6-10$ years & 205 & 22 \\
\hline $11+$ years & 99 & 11 \\
\hline \multicolumn{3}{|l|}{ Management of diabetes } \\
\hline Diet/Exercise & 367 & 41.3 \\
\hline $\mathrm{OHA}$ & 198 & 22.3 \\
\hline Insulin & 231 & 26.0 \\
\hline Combination (Insulin + OHA) & 92 & 10.4 \\
\hline
\end{tabular}

Results are expressed as number (percentage) and mean \pm SD.
Table 2 Prevalence of overweight and obesity according to BMI ( $\mathbf{n}=\mathbf{8 8 8})$

\begin{tabular}{lcc}
\hline Variables & Prevalence (\%) & $\mathbf{9 5 \% ~ C l}$ \\
\hline Overweight (23-24.9) & 22 & $19-24$ \\
Obese (>25) & 48 & $45-51$ \\
\hline Results are expressed as number, percentage and Confidence Interval (CI).
\end{tabular}

population) were used to assess central obesity [21-24]. Cut off points of overweight and obesity for both sexes were $\geq 23-24.9 \mathrm{~kg} / \mathrm{m}^{2}$ and $\geq 25 \mathrm{~kg} / \mathrm{m}^{2}$ respectively. Cut off points of waist circumference for men and women were $\geq 90$ and $\geq 80 \mathrm{~cm}$, WHR for men $\geq 0.90$ and women $\geq 0.80$ and WHtR for both sexes were $\geq 0.50$ respectively.

All data were expressed as the mean \pm SD and percentage. To assess the significant association of quantitative data Pearson's correlation coefficient with p-values was calculated to explore the association between two variables. Binary logistic regression were performed to quantify the individual effect of predictor variables and to adjust for potential confounding factors. The statistical tests were considered significant at a level $\leq 5 \%(\leq 0.05)$. Data were presented by tables and graphs. All the statistical analysis was performed using SPSS 17 software.

\section{Results}

\section{Patient's characteristics}

Age of the study participants ranged between 15 and 49 years with a mean $( \pm S D)$ age of $39 \pm 7$ years. About half of the participants were in the age group of 35-44 years $(43.7 \%)$. The higher proportion of the participants was housewives (94.9\%). Majority of participants (43\%)

Table 3 Anthropometric indices of the study subjects ( $\mathbf{n}=\mathbf{8 8 8}$ )

\begin{tabular}{|c|c|c|}
\hline Mean \pm SD variables & Number & Percentage \\
\hline BMI (Mean \pm SD) & \multicolumn{2}{|c|}{$25 \pm 4$} \\
\hline Underweight $(<18.5)$ & 35 & 4 \\
\hline Normal (18.5-22.9) & 234 & 26 \\
\hline Overweight (23-24.9) & 192 & 22 \\
\hline Obese (>25) & 427 & 48 \\
\hline WC (in cm) (Mean \pm SD) & \multicolumn{2}{|c|}{$88 \pm 11.2$} \\
\hline Normal $(<80)$ & 204 & 23 \\
\hline Health Risk (>80 \& above) & 684 & 77 \\
\hline WHR (Mean \pm SD) & \multicolumn{2}{|c|}{$0.97 \pm 0.08$} \\
\hline Normal $(<0.80)$ & 1 & 0.1 \\
\hline Health Risk (>0.80 \& above) & 887 & 99.9 \\
\hline WHtR (Mean \pm SD) & \multicolumn{2}{|c|}{$0.58 \pm 0.08$} \\
\hline Normal $(<0.50)$ & 5 & 11 \\
\hline Health Risk (>0.50 \& above) & 883 & 89 \\
\hline
\end{tabular}

Results are expressed as number (percentage) and mean $\pm \mathrm{SD}, \mathrm{BMI}=\mathrm{Body}$ mass index, $\mathrm{WC}=$ Waist circumference, $\mathrm{WHR}=$ Waist to hip ratio, $\mathrm{WHtR}=$ Waist to height ratio. 
Table 4 Association of anthropometric indices with other variables

\begin{tabular}{|c|c|c|c|c|}
\hline Variables & BMI & WC & WHR & WHtR \\
\hline & $r / p$ & $r / p$ & $r / p$ & $r / p$ \\
\hline Age & $.135 / .001$ & $.162 / .001$ & $.051 / .126$ & $.139 / .001$ \\
\hline Income & $.151 / .001$ & $.087 / .009$ & $.094 / .005$ & $.069 / .04$ \\
\hline Duration of diabetes & $-.015 / .665$ & $.057 / .088$ & $.051 / .131$ & $.073 / .03$ \\
\hline Energy intake & $.001 / .998$ & $.017 / .619$ & $-.035 / .296$ & $.000 / .976$ \\
\hline
\end{tabular}

The level of significance at $p<0.05 ; r=$ correlation coefficient.

were educated up to primary level and $58 \%$ of the participant's belonged from lower middle class (monthly household income between 5361 and 21270 taka) (Table 1).

\section{Prevalence of overweight and obesity}

The overall prevalence of overweight was 22\% (95\% CI 19-24) and that of obesity was 48\% (95\% CI 45-51) (Table 2). Prevalence of central obesity by waist circumference was $77 \%$, by waist-hip ratio was $99.9 \%$ and by WHtR 89\% (Table 3). Overweight and obesity were higher in the age group of 45-49 years (49\%) and 35-44 years $(24 \%)$ respectively.

\section{Determinants of overweight and obesity}

The Table 4 demonstrates correlation coefficient generated through Pearson correlation. Age and income were significantly correlated with BMI $(\mathrm{r}=0.135, \mathrm{p}=0.001 ; \mathrm{r}=$ $0.151, \mathrm{p}=0.001)$, WC $(\mathrm{r}=0.162, \mathrm{p}=0.001 ; \mathrm{r}=0.087, \mathrm{p}=$ $0.009)$ and WHtR $(\mathrm{r}=0.139, \mathrm{p}=0.001 ; \mathrm{r}=0.069, \mathrm{p}=0.04)$ respectively. Where, only income was correlated with WHR ( $\mathrm{r}=0.094, \mathrm{p}=0.005)$. On the other hand, duration of diabetes was significantly correlated only with WHtR ( $\mathrm{r}=0.073, \mathrm{p}=0.03)$.
On binary logistic regression analysis, BMI was significantly associated with age $(\mathrm{p}<0.05)$, income $(\mathrm{p}<0.05)$ and management of diabetes by OHA $(\mathrm{p}<0.05)$. On the other hand, WC was significantly associated with age ( $\mathrm{p}<$ $0.001)$, income $(\mathrm{p}<0.05)$, management of diabetes by OHA $(\mathrm{p}<0.05)$ and insulin $(\mathrm{p}<0.05)$. WHR was significantly associated only with duration of diabetes $(\mathrm{p}<0.05)$ and WHtR was significantly associated with age $(\mathrm{p}<0.05)$, management of diabetes by OHA $(\mathrm{p}<0.05)$ and insulin $(\mathrm{p}<0.05)$ (Table 5).

\section{Discussion}

Noticeably, overweight or obesity is associated with high mortality, disability, and a poor quality of life [25]. Research showed that current rate of overweight and obesity are already unacceptably high among women [26]. This is of considerable concern for number of reasons. This is the risk factor of diabetes mellitus, hypertension, dyslipidemia, CHD, depression and various type of cancer. This increasing trend of overweight and obesity, when combined with the continued trend toward globalization, will serve to seriously escalate the population level of obesity. This study showed that $22 \%$ and $48 \%$ of the Bangladeshi diabetic women of reproductive age are overweight and obese respectively according to Asian specific BMI cut-off value. Thus the results of the present study show that overweight and obesity are major public health problems for reproductive age women in Bangladesh. No study was conducted on Bangladeshi diabetic women of reproductive age for measuring overweight and obesity previously. In Saudi Arab, El Hazmi et al. [27] conducted a study, where $29.66 \%$ and $39.27 \%$ diabetic women were found overweight and obese respectively by using WHO standard

Table 5 Logistic regression coefficient and odds ratio $(95 \% \mathrm{Cl})$ of determining variables considering different variable

\begin{tabular}{|c|c|c|c|c|c|c|c|c|}
\hline \multirow[t]{2}{*}{ Variables } & \multicolumn{2}{|r|}{ BMI } & \multicolumn{2}{|r|}{ WC } & \multicolumn{2}{|c|}{ WHR } & \multicolumn{2}{|c|}{ WHtR } \\
\hline & P-value & OR $(95 \% \mathrm{Cl})$ & P-value & OR $(95 \% \mathrm{Cl})$ & P-value & OR $(95 \% \mathrm{Cl})$ & P-value & OR $(95 \% \mathrm{Cl})$ \\
\hline$\overline{\text { Age }}$ & 0.001 & $1.04(1.02-1.06)$ & 0.001 & $1.03(1.01-0.06)$ & 0.706 & $0.98(0.93-1.04)$ & 0.003 & $1.04(1.02-1.07)$ \\
\hline Income & 0.016 & $1.00(1.0-1.0)$ & 0.030 & $1.00(1.0-1.0)$ & 0.865 & $1.00(1.0-1.0)$ & 0.249 & $1.00(1.0-1.0)$ \\
\hline Duration of diabetes & 0.513 & $0.98(0.95-1.02)$ & 0.438 & $1.01(0.97-1.05)$ & $0.013^{*}$ & $1.25(1.04-1.49)$ & 0.506 & $1.02(0.9-1.1)$ \\
\hline
\end{tabular}

Management of diabetes

Diet/exercise*

$\mathrm{OHA}$

Insulin

Combination

Exercise habit

No*

Yes

Energy intake
Reference

$$
0.047
$$

0.567

$$
1.88(1.2-2.8)
$$

$1.11(0.77-1.5)$

0.611

$1.14(0.68-1.9)$
Reference

\subsection{1}

0.013

0.583

$$
4.16 \text { (2.4-7.1) }
$$

$1.65(1.1-2.4)$

$1.16(0.68-1.9)$
Reference

0.441

0.495

0.943
$1.59(0.48-5.2)$

0.70 (0.25-1.9)

0.94 (0.19-4.5)
Reference

$0.003 \quad 2.64(1.4-5.0)$

0.001

$2.53(1.43-4.4)$

$1.47(0.72-2.9)$

*: Reference group, $\beta$ for standardized regression coefficient, BMI, WC, WHR and WHtR were taken as dependent variables whereas others taken as independent variables. Significant at $\mathrm{p}$-value $<0.05$ levels, $\mathrm{Cl}=$ Confidence Interval, $\mathrm{OR}=$ odds ratio, $\mathrm{OHA}=$ Oral Hypoglycemic Agent. 
BMI cut off value. Our study showed more prevalence of overweight and obesity in our population. Probably the cut-off value of BMI and ethnicity are the leading cause of difference of this result. Khan et al. [25] conducted a study among ever-married non-pregnant urban women in Bangladesh. They had found 15.7\% and 3.9\% of participants were overweight and obese respectively. The probable reason of difference may be due to the study population and cut-off values. But now this situation has changed dramatically due to rapid demographic transition from traditional lifestyle to modern culture. The prevalence of obesity has reached on its peak, near about $100 \%$, among both Saudi Arabian and Bangladeshi women. The current study found $77 \%$ respondent had excess waist circumference and its mean was $88.0 \pm 11.2 \mathrm{~cm}$. Anisur et al. [28] found 23\% urban women at Dhaka had excess waist circumference, which is much lower than our study findings. Surprisingly, almost hundred percent (99.9\%) diabetic women had excess cut-off value of waist to hip ratio and they fall in the higher risk group of obesity related disorders in this study. Most of the respondents had abnormal waist to height ratio (89\%). Women had more body fat composition than men and the values are probably high due to the inclusion of the diabetic population in this study.

The highest prevalence of overweight and obesity has been reported in women aged 35-49 age groups and correlation curve show that BMI, waist circumference and waist-height ratio are increased with advancement of age. This result was similar with Sotoudeh et al. [29] also found that obesity is increased with age. The higher income group people have a sedentary lifestyle and it can induce obesity. The present study shows that increasing household income is associated with anthropometric markers (BMI, WC, WHR and WHtR). Duration of diabetes is also positively associated with waist to height ratio. In present study, by multivariate analysis, age, income levels and duration of diabetes are found to independently correlate with overweight and central obesity. Using of oral hypoglycemic drug for treatment of diabetes is found to create abnormal anthropometric risk markers among diabetic reproductive aged women. OHA users had near about 4 times higher chance of development of central obesity and 2 times higher chance of over weight than the lifestyle modification adopting groups. Drug trials showed that some $\mathrm{OHA}$ can induce obesity [30] and which support our research findings. As the samples were drawn from one hospital, several factors may have impact on the results as to limit its generalizability. However, as mentioned earlier BIRDEM is an institute of the Diabetic Association of Bangladesh (DAB), which functions as a referral hospital for whole of Bangladesh through DAB's nationwide referral centers.

\section{Conclusions}

The prevalence of overweight and obesity among women of reproductive age seems to be a critical public health concern. A high prevalence of both overweight and obesity exists in diabetic women of reproductive age in Bangladesh and it seems to be associated with increasing age, income, duration of diabetes, management of diabetes especially use of oral hypoglycemic agent. Our findings confirm and reinforce the need for further attention to the health and wellbeing of women of reproductive age to prevent the epidemic of overweight and obesity.

\section{Ethical consideration}

This study was approved by the Ethical Review Committee of Diabetic Association of Bangladesh (BADAS). Written informed consent was obtained from the all participants. Ethics has been respected throughout the whole study period.

\section{Competing interests}

The authors declare that they have no competing interests.

\section{Authors' contribution}

JA contributed her intellectual ability to conception and design of the research analysis and interpretation of data; drafting the article and revising it critically for important intellectual content; and final approval of the version to be published. SH, KRA, BRA, HAC participated on drafting the article and revising it critically for important intellectual content; interpretation of data and final approval of the version to be published. MS, $K F$, and $L A$ revises the manuscript for important intellectual content, works on analysis and interpretation of data; and final approval of the version to be published. All authors' read and approved the final manuscript.

\section{Acknowledgements}

We would like to thank Bangladesh University of Health Sciences (BUHS) for giving us the opportunity to do this research. We are indebted also data collectors and respondents, health centers. Our special thanks go to the World Diabetes Federation (WDF) for financial support.

\section{Author details}

${ }^{1}$ Department of Reproductive and Child Health, Bangladesh University of Health Sciences (BUHS), Darus Salam, Mirpur, Dhaka 1216, Bangladesh. ${ }^{2}$ Department of Public Health, Daffodil International University (DIU), Dhaka, Bangladesh. ${ }^{3}$ Department of Health Promotion and Heath Education, BUHS, Darus Salam, Mirpur, Dhaka 1216, Bangladesh. ${ }^{4}$ Department of Biostatistics, BUHS, Darus Salam, Mirpur, Dhaka 1216, Bangladesh. ${ }^{5}$ School of Public Health and Community Medicine, University of New South Wales, Sydney, Australia. ${ }^{6}$ Department of Biochemistry and Cell Biology, BUHS, Dhaka 1216, Bangladesh.

Received: 23 March 2014 Accepted: 4 August 2014

Published: 11 August 2014

\section{References}

1. Kumanyika S, Jeffery RW, Morabia A, Ritenbaugh C, Antipatis VJ: Obesity prevention: the case for action. Int J Obes 2002, 26:425-436.

2. WHO (World Health Organization): The World Health Report: Reducing Risks, Promoting Healthy Life. Geneva: World Health Organization; 2002.

3. WHO (World Health Organization): Obesity: Preventing and Managing the Global Epidemic. Report of WHO Consultation on Obesity. Geneva: WHO; 1998.

4. WHO (World Health Organization): Diet, Nutrition and the Prevention of Chronic Diseases. Report of a joint WHO/FAO expert consultation. Technical Report Series No. 916. Geneva: World Health Organization; 2003. 
5. WHO (World Health Organization), International Association for the Study of Obesity (IASO) and International Obesity Task Force (IOTF): The Asia-Pacific Perspective: Redefining Obesity and its Treatment. Geneva: World Health Organization; 2000.

6. Shafique S, Akhter N, Stallkamp G, de Pee S, Panagides D, Bloem MW: Trends of under- and overweight among rural and urban poor women indicate the double burden of malnutrition in Bangladesh. Int J Epidemiol 2007, 36:449-457.

7. Caballero B: The global epidemic of obesity: an overview. Epidemiol Rev 2007, 29:1-5.

8. Clément K, Ferré P: Genetics and the pathophysiology of obesity. Pediatr Res 2003, 53:721-725.

9. U.S. Department of Health and Human Services: The Surgeon General's Call to Action to Prevent or Decrease Overweight and Obesity. Rockville, MD: U.S. Department of Health and Human Services, Public Health Service, Office of the Surgeon General; 2001

10. Zaadstra BM, Seidell JC, Van Noord PA, te Velde ER, Habbema JD, Vrieswijk B, Karbaat J: Fat and female fecundity: prospective study of effect of body fat distribution on conception rates. BMJ 1993, 306:484-487.

11. Catalano PM: Management of obesity in pregnancy. Obstet Gynecol 2007, 109:419-433.

12. Cedergren MI: Maternal morbid obesity and the risk of adverse pregnancy outcome. Obstet Gynecol 2004, 103:219-224.

13. Pathi A, Esen $U$, Hildreth A: A comparison of complications of pregnancy and delivery in morbidly obese and non-obese women. J Obstet Gynaecol 2006, 26(6):527-530.

14. Robinson HE, O'Connell CM, Joseph KS, McLeod NL: Maternal outcomes in pregnancies complicated by obesity. Obstet Gynecol 2005, 106(6):1357-1364.

15. Fretts RC: Etiology and prevention of stillbirths. Am J Obstet Gynecol 2005, 193:1923-1935

16. Ramsay J, Greer I, Sattar N: Obesity and reproduction. BMJ 2006, 333:1159-1162

17. Mendez MA, Monteiro CA, Popkin BM: Overweight exceeds underweight among women in most developing countries. Am J Clin Nutr 2005, 81:714-721.

18. Yarlini B, Eduardo V: Nationally representative surveys show recent increases in the prevalence of overweight and obesity among women of reproductive age in Bangladesh, Nepal, and India. J Nutr 2009, 2144:2139-2144. doi:10.3945/jn.109.112029.

19. Summarized data of Knowledge Attitude and Practice (KAP) study: World Diabetes Foundation (WDF 05-131): Improving Nutrition in Bangladeshi Population- From Research to Practice. Available at: www.pushti.org/ Summarized data of KAP study.xls.

20. Nurul Haque ANM: The middle-income matrix. Daily Star 2007, 18:11-18.

21. Choo V: WHO reassesses appropriate body-mass index forAsian populations. Lancet 2002, 360:235.

22. World Health Organization: Western Pacific Region. The International Association for the Study of Obesity and the International Obesity Task Force. The Asia-Pacific Perspective: Redefining Obesity and its Treatment. Sydney, Australia: Health Communications Australia Pty Limited; 2000 [Available: http://www.wpro.who.int/nutrition/documents/docs/Redefiningobesity.pdf].

23. Margaret A, Sigrid $\mathrm{G}$ : Waist to height ratio is a simple andeffective obesity screening toll for cardiovascular risk fac-tors: analysis of data from the British National Diet andNutrition Survey of Adult aged 19-64 years. Obes Facts 2009, 2:97-103.

24. Lee CM, Huxley RR, Wildman RP, Woodward M: Indices ofabdominal obesity are better discriminators of cardiovascu-lar risk factors than BMI: a meta-analysis. J Clin Epidemiol 2008, 61:646-653.

25. Khan MMH, Kraemer A: Factors associated with being underweight, overweight and obese among ever-married non-pregnant urban women in Bangladesh. Singapore Med J 2009, 50(8):804.

26. Jafar TH, Nish C, Gregory P: Prevalence of overweight and obesity and their association with hypertension and diabetes mellitus in an IndoAsian population. CMAJ 2006, 17(9):1071-1077.

27. El-Hazmi MAF, Warsy AS: Prevalence of overweight and obesity in diabetic and non-diabetic Saudis. East Mediterr Health J 2000, 6:276-282.
28. Anisur R, Monira Akhter M, Kamal A, Shafiqul I, Abidul H: Anthropometric profile of the urban senior citizens. Ibrahim Med Coll J 2010, 4(2):59-62.

29. Sotoudeh G, Khosravi S: Farahnaz Khajehnasiri and Hamid Reza Khalkhali. High prevalence of overweight and obesity in women of Islamshahr, Iran. Asia Pac J Clin Nutr 2005, 14(2):169-172.

30. Zimmerman BR: Sulfonylureas. Endocrinol Metab Clin North Am 1997. 26:511-521

doi:10.1186/1756-0500-7-513

Cite this article as: Akter et al:: Determinants of overweight and obesity among Bangladeshi diabetic women of reproductive age. BMC Research Notes 2014 7:513.

\section{Submit your next manuscript to BioMed Central and take full advantage of:}

- Convenient online submission

- Thorough peer review

- No space constraints or color figure charges

- Immediate publication on acceptance

- Inclusion in PubMed, CAS, Scopus and Google Scholar

- Research which is freely available for redistribution 